\title{
Facilitating a Multi-Lateral Solution to Water Quality Impairments of the Savannah Harbor
}

\author{
Clifton F. Bell ${ }^{*}$, Thomas Gallo², Sandra Ralston², and Ed Saxon ${ }^{3}$
}

\begin{abstract}
AUTHORS: ${ }^{1}$ Brown and Caldwell, Virginia Beach, Virginia 23452, ${ }^{2}$ Malcolm Pirnie ARCADIS, Charleston, South Carolina, 29492, ${ }^{3}$ Beaufort-Jasper Water \& Sewer Authority, Okatie, South Carolina 29909.

REFERENCE: Proceedings of the 2012 South Carolina Water Resources Conference, held October 10-11, 2012 at the Columbia Metropolitan Convention Center
\end{abstract}

\begin{abstract}
In 2010, the USEPA published a draft total maximum daily load (TMDL) to address nonattainment of dissolved oxygen (DO) criteria in the Savannah Harbor. The draft TMDL calls for severe (75$90 \%$ ) reductions in point source discharges of biological oxygen demand. Rather than assigning wasteload allocation (WLAs) to individual dischargers, USEPA and state regulators provided dischargers with the unusual opportunity to determine among themselves how to best distribute the WLA. It was hoped that this discharger-led process would lead to a solution that is more equitable and acceptable than one imposed by regulatory agencies. The combined discharger group retained Malcolm Pirnie ARCADIS in the summer of 2010 to facilitate the yearlong WLA distribution process.
\end{abstract}

The combined discharger group was highly diverse, with a membership that included large pulp and paper mills, publically-owned treatment plants of varying sizes, and other industries. Natural dichotomies within the group included municipal versus industrial interests, Georgia versus South Carolina interests, and small versus large discharger interests. The group devised a strategy that relied on moving from agreement on general equity principals, then to potential WLA distribution scenarios, and finally to one preferred WLA scenario. Major equity issues that the group identified included:

- Every discharger should contribute to the solution.

- More impacting facilities should do more.

- Past achievements should be rewarded.

- There should be equity between the states of Georgia and South Carolina.

- Economic hardship should be considered.

The discharger group ultimately chose a solution whereby load reductions were made proportional to each facility's impact on DO under baseline loading conditions. However, load reduction "caps" and technology-based concentration "floors" were also used to help ensure that no discharger received unattainable limits. The chosen solution represents a 396,281 lb/day reduction in ultimate oxygen demand loading from existing permitted conditions, and a 72 percent total load reduction, and would make approximately 98 percent of the progress needed to eliminate the excess DO deficit in the Savannah Harbor.

\section{INTRODUCTION}

The Savannah River drains area of almost 10,600 square miles of Georgia and South Carolina, and serves as the boundary between the two states. The Savannah Harbor is shared by both states and was placed on Georgia's 2002 Section 303(d) list due to low dissolved oxygen (DO). It was generally recognized that the system was significantly overallocated for oxygen-demanding substances such as carbonaceous biological oxygen demand (CBOD) and ammonia nitrogen. USEPA published a total maximum daily load (TMDL) in 2006, and after additional monitoring and modeling efforts, published a revised TMDL in 2010.

The draft TMDL called for large (75-90\%) reductions in point source discharges of biological oxygen demand. The TMDL listed 23 major dischargers to the system, including larger pulp \& paper mills, both large and small municipal wastewater treatment plants, and other industries. Rather than assigning wasteload allocation (WLAs) to individual dischargers, USEPA and state regulators provided dischargers with the unusual opportunity to determine among themselves how to best distribute the WLA. It was hoped that this one-year, discharger-led process would lead to a solution that was more acceptable than one imposed by regulatory agencies. This paper describes the staged, facilitated process that the discharger group undertook to determine and document individual WLAs. 


\section{METHODS}

As of 2010, most of major dischargers to the Savannah River/Harbor were already organized into two coalitions called the Savannah Harbor Committee and Central Savannah River Area TMDL Group. In the summer of 2010, these two groups came together for the purposes of initiating a one-year WLA distribution process. Malcolm Pirnie ARCADIS was retained in late summer 2010 as the group facilitator. In October of 2010, the group embarked on a series of meetings, communications, and technical analyses to support the discussions.

The process was designed to progress from the discussion of broad equity concepts (stage 1), to the exploration of alternatives (stage 2), to the agreement on specific WLAs (stage 3). Prior to the first (stage 1) meeting, the facilitator interviewed representatives from each facility, primarily to map out major perspectives and expectations. The facilitator also conducted a written survey to verify each facility's permitting loadings, historical loadings, and treatment processes.

The entire process involved four facilitated meetings, including one stage 1 meeting, two stage 2 meetings, and one stage 3 meeting. The meeting setup was such that each discharger had one representative at the main table, and each discharger had one equal vote on key decisions. Secondary representatives were present but could only speak during specified times. Regulators were not present at the Stage 1-3 meetings. However, at the end of the one-year process, the group held a joint meeting with USEPA, the Georgia EPD, and the South Carolina DHEC to present the results of the WLA distribution process. In between meetings, dischargers provided written feedback on prior meetings and also reviewed technical document prepared by the facilitator.

\section{RESULTS}

\section{Stage 1 - Agreeing on Process of Equity Concepts}

During the stage 1 meeting on October 2010, the combined discharger group agreed on the common goal of achieving a WLA distribution that was approvable by regulators, implementable, fair, scientifically sound, and supportive of regional economic growth. The group compiled a list of major equity concepts, including the following:

- All dischargers should "do their share".

- Expectation of more effort from higherimpacting facilities than lower-impacting facilities.
- Dischargers should receive credit for past/present achievements.

- WLA should be equitably distributed between Georgia and South Carolina.

- WLA should be distributed based on actual needs of existing facilities.

- Economic hardship on industries or communities should be considered.

It was recognized that some of the equity concepts were in tension with each other and that the ultimate solution would likely represent a balance between multiple equity concepts. During the stage 1 meeting, the group reviewed various families of WLA distributions methods, and agreed to explore several including:

- Equal percent load reduction.

- Equal impact on DO in critical segment(s).

- Different splits of WLA between Georgia and South Carolina dischargers.

- Different splits of impact on DO between Georgia and South Carolina dischargers.

- Tiered reductions (i.e., more impacting facilities to achieve higher percent load reduction).

- Load reductions proportional to baseline impact.

\section{Stage 2 - Evaluating Alternatives}

Over the course of two subsequent stage 2 meetings, these methods were explored and narrowed. The group explored reductions from two different baselines: one representing existing permitted loading, and the other representing a technology baseline. The technology baseline was intended to represent best practicable treatment (BPT) for industrial dischargers and secondary treatment for municipal facilities.

Over the course of the stage 2 communications, the discharger group narrowed the list of preferred WLA distribution scenarios and ultimately reached consensus on the scenario family entitled "load reductions proportional to baseline impact". In general, it was felt that this approach was an effective means of addressing the equity concepts that "everyone do their share" but that high-impacting dischargers do more. It was also found that this scenario tended to provide South Carolina with a slightly higher share of the total DO impact than under existing permitted conditions, which was considered a desirable outcome by some dischargers.

During stage 2, dischargers also reached consensus on the need to include certain provisions in the allocation method to prevent some dischargers from receiving WLAs that were technologically or economically 
unattainable. These provisions included caps on the maximum percent load reduction that any facility would be expected to bear and technology-based concentration floors for both 5-day carbonaceous biological oxygen demand $\left(\mathrm{CBOD}_{5}\right)$ and ammonia nitrogen $\left(\mathrm{NH}_{3}-\mathrm{N}\right)$. It was recognized that the WLA distribution method could produce very different results from some dischargers, depending on at what level the maximum load reductions caps were set.

\section{Stage 3 - Selecting the Preferred Option}

By the stage 3 meeting held in May 2011, it was clear that the group had made tremendous progress in agreeing to load reductions that greatly reduced the non-attainment of DO criteria in the Savannah Harbor. However, the scenario also showed a relatively small amount of remaining non-attainment that resulted from a combination of factors including treatability limits and allocation rules aimed at producing equity. Although small when expressed as a percentage of the total progress needed, the attainability gap was challenging from a load reduction and equity standpoint. Bridging of the gap had the potential to push some dischargers beyond treatability limits, or conversely, could cause some lower impacting dischargers to make much higher reductions from baseline loading levels.

A major focus of the stage 3 meeting was discussion of various options for bridging the attainment gap such as lower technology-based concentrations floors, use of DO injection, and higher reductions from specific facilities. Although some of these options (or combinations thereof) were considered to be potentially viable, the group also identified several key uncertainties that could have a strong influence on exactly how the final attainment gap was bridged. These included technical and regulatory aspects of DO injection, how the cost/responsibility of DO injection would be shared, and the details of credit trading/offset program.

Given these uncertainties, the discharger group ultimately reached consensus to pursue a TMDL waste load allocation with regulators that includes two components: (1) an individual discharger reduction component; and (2) an additional aggregate reduction, the equitable allocation of which would be deferred for determination. The first component (individual discharger load reductions) would include the majority of the implementation progress and would also allow for resolution of the key issues needed to bridge the final attainment gap during permit development and implementation. The component 1 allocations represent a 396,212 lb/day reduction in UOD from existing permitted conditions and a 72 percent total UOD load reduction. Determination of component 2 allocations will require additional studies and discussions, and is expected to commence in the fall of 2011.

\section{CONCLUSIONS}

The Savannah Harbor experience shows the potential benefits of discharger-led decision-making in the TMDL and WLA process. The resulting WLAs are very stringent and costly for many dischargers, as would be WLAs simply imposed by regulators. However, the facilitated process achieved a much higher level of buyin that otherwise possible. This can be primarily attributed to the cooperative, staged manner in which the group agreed on equity concepts, evaluated a range of outcomes, and ultimately selected an outcome that most closely matched the selected equity model. The process was enhanced by open communications, a relatively high degree of trust, and the recognition that group success was also in the interest of individual facilities. The Savannah Harbor WLA process provides a model for resolving conflict in other potentially controversial TMDLs. 